\title{
Fungal diversity in high Andean ecuadorian forest soil
}

\author{
Adrian Valdez ${ }^{1}$ and Sergio Covarrubias ${ }^{2}$ \\ ${ }^{1}$ Universidad de Talca \\ ${ }^{2}$ Universidad Autónoma de Zacatecas
}

March 11, 2021

\begin{abstract}
The Andes range in Ecuador presents high biodiversity and characteristic altitudinal gradients, which are frequently threatened by deforestation and farming. In particular, forest have developed in the high inter-Andean alley on volcanic soils forming a unique ecoregion. Little is known on the fungal biodiversity of soil in such high Andean gallery forest submitted to strong degradation pressures. Therefore, in this study we evaluated wether the soil mycobiome was associated with altitudinal gradients during the dry season. Three representative locations were selected based on altitude: A (3,309 meters above the sea level, masl), B (3,809 masl) and C (4,409 masl). High performance sequencing (NGS) of the ITS region of ribosomal DNA genes with Illumina technology was used to explore the fungal taxonomic composition in the soil samples. Our results showed changes in the structure of fungal communities in the different locations, related to the relative abundance of Amplicon Sequence Variants (ASV). Higher fungal diversity was related with the altitudinal gradient with average taxa ranging from 675,626 and 556 ASVs, respectively from location A to C. The results highlight the complexity and diversity of fungal communities in high Andean forest and the need to protect these unique mycobiomes. The findings in this ecosystem of Ecuador will improve our understanding of distribution, diversity, ecology, and biological perspectives for the restoration of terrestrial microbiomes.
\end{abstract}

\section{INTRODUCTION}

The forest soil in the Andean highlands has high biodiversity and unique environmental characteristics. It is an endangered ecosystem, and little is known about its microbial composition. It is estimated that metagenomic DNA samples taken from undisturbed soil may contain 6,000 to 10,000 different microbial genomes (Torsvik \& Øvreås 2002). Soil metagenomes can potentially reveal patterns of variation in the functionality of the soil biota and, from them, the general ecological patterns of community structure and ecosystem function (Fierer 2017).

With the exception of the some studies (Keating 1998; Thies et al. 2012), there is limited information on deforestation rates in South Ecuador, an important front of deforestation in the country. At the same time, this region is of particular interest and value for biodiversity conservation (Sierra et al. 2002), and to obtain valuable information about the microbiological components in this type of biomes (Tapia-Armijos et al. 2015).

Although many studies have shown that changes in environmental conditions are important drivers of changes in soil microbial diversity (Pausas \& Bond 2020), this has been poorly documented in closed biome. There is reason to believe that the spatial diversity and richness of fungi among soil samples could save a close relationship when it is under a closed biome (Pausas \& Bond 2020). The biome concept was first introduced to characterize structurally similar vegetation types in similar climates around the world. The biomes are representing distinct climate zones with unique characteristics (Moncrieff 2016). Closed biomes are forests, that is, tree-dominated ecosystems in which the density and leaf area is high enough to exclude shadeintolerant plants in the understory. Closed biomes typically have higher plant biomass than open biomes (Pausas \& Bond 2020). 
Fungi represent an essential functional component of terrestrial ecosystems as decomposers, mutualists, and pathogens, and they are one of the most diverse groups of Eukarya (Mueller et al. 2007). The study of the ecological factors that underlie the dynamics of fungal communities remains a challenge due to this high taxonomic and ecological diversity (Nordén et al. 2001; Genney et al. 2005; Koide et al. 2007). Moreover, microorganisms have a major impact on ecological restoration to recover soil functions although they have been rarely considered or incorporated into these restorative efforts (Donald et al. 2018).

The introduction of molecular biology and tools such as Sanger sequencing significantly increased the ability to characterize communities of microbes in situ (Malik et al. 2008; Stockinger et al. 2010). Recently, the advent of next-generation or high sequencing technology's performance (NGS) have generated greater knowledge at an ever-faster pace (Lindahl et al. 2013; Van der Heijden et al. 2015). In the last decade, metagenomic analyses of microbial communities have become useful tools in the study of new microorganisms, genes, or biotechnological products (Steele \& Streit 2005; Schmeisser et al. 2007; Steele et al. 2009), which are present in soil microbial communities without the need to cultivate them in vitro (Jansson et al. 2018).

The internal transcribed spacer region (ITS) is now widely used as a marker and DNA barcode validated for the identification of many species of fungi (Seifert 2009). With improvements in sequencing techniques and DNA databases recent studies have demonstrated the potential of high-performance ITS sequencing to quantify and characterize the fungal diversity of the soil (Kõljalg et al. 2005; Peay et al. 2016).

Recently, new methods have been developed that resolve amplicon sequence variants (ASVs) from Illuminascale amplicon data without imposing the arbitrary dissimilarity thresholds that define molecular Operational Taxonomic Unit (OTUs) (Eren et al. 2013; Tikhonov et al. 2015; Eren et al. 2015; Callahan et al. 2016; Edgar 2016; Amir et al. 2017). ASV methods infer biological sequences in the sample prior to the introduction of amplification and sequencing errors and distinguish sequence variants differing by as little as one nucleotide. A similar class of methods developed for 454-scale data was typically used to 'denoise' sequencing data prior to constructing OTUs (Quince et al. 2011), while new ASV methods are explicitly intended to replace OTUs as the atomic unit of analysis. ASV methods have demonstrated sensitivity and specificity as good as or better than OTU methods and better discrimination of ecological patterns (Eren et al. 2013; Eren et al. 2015; Callahan et al. 2016; Needham et al. 2017).

In this article, we use high-throughput DNA sequencing to explore the diversity of soil fungi in high Andean forests of the closed biome, and observe the relationship with the altitudinal gradient, in three locations of the southern region of Ecuador, through the construction of metagenomic libraries, using Illumina technology, with an emphasis in microbiological soil restoration programs.

\section{MATERIALS AND METHODS}

Sample collection

The study site was located in the Chuchucán forest, a mountain area in Cañar-Ecuador. In July 2019, 100 soil samples were collected at three altitudes (Table 1, Figure 1.), where the vegetation was composed by dense closed forest called the cerrado biome, where the most representative species are: Oreopanax ecuadorensis, Prumnopitys philippi, Myrcianthes rhopaloides, belonging to the Araliaceae, Podocarpaceae and Myrtaceae families respectively. These species form a dense tree canopy 2-4 $\mathrm{m}$ tall, without understory shrubs and grass layer.

Table 1. Soil sampling locations, altitude and geographic coordinates of the closed biome forest Chuchucán.

\begin{tabular}{lll}
\hline Locations & Altitude (masl) & Coordinates \\
\hline A & 3,309 & $2^{\mathrm{o}} 32^{\prime} 13.056^{\prime \prime} \mathrm{S} ; 79^{\mathrm{o}} 1^{\prime} 45.16^{\prime \prime} \mathrm{W}$ \\
$\mathrm{B}$ & 3,815 & $2^{\mathrm{O}} 31^{\prime} 56.1747^{\prime \prime} \mathrm{S} ; 79^{\mathrm{o}} 011^{\prime} 05.8023^{\prime \prime} \mathrm{W}$ \\
C & 4,410 & $2^{\mathrm{O}} 32^{\prime} 12.7859^{\prime \prime} \mathrm{S} ; 79^{\mathrm{o}} 00^{\prime} 39.9244^{\prime \prime} \mathrm{W}$ \\
\hline
\end{tabular}


A soil sampler was used to collect the soil samples $(5 \times 5 \times 20 \mathrm{~cm}$; length $\times$ width $\times$ depth $)$. The samples were transported to the laboratory $(<2 \mathrm{~h})$ and stored at $-80{ }^{\circ} \mathrm{C}$ until DNA extraction. An organic $(0-10 \mathrm{~cm})$ and a mineral $(10-20 \mathrm{~cm}$ ) lay separations were performed in the laboratory for each biological replica (the core of the soil). Sampled soil was sifted $(2 \mathrm{~mm}$ mesh) and homogenized prior to molecular analysis for each replica, while replicas were grouped for soil analysis (Uroz et al. 2013).

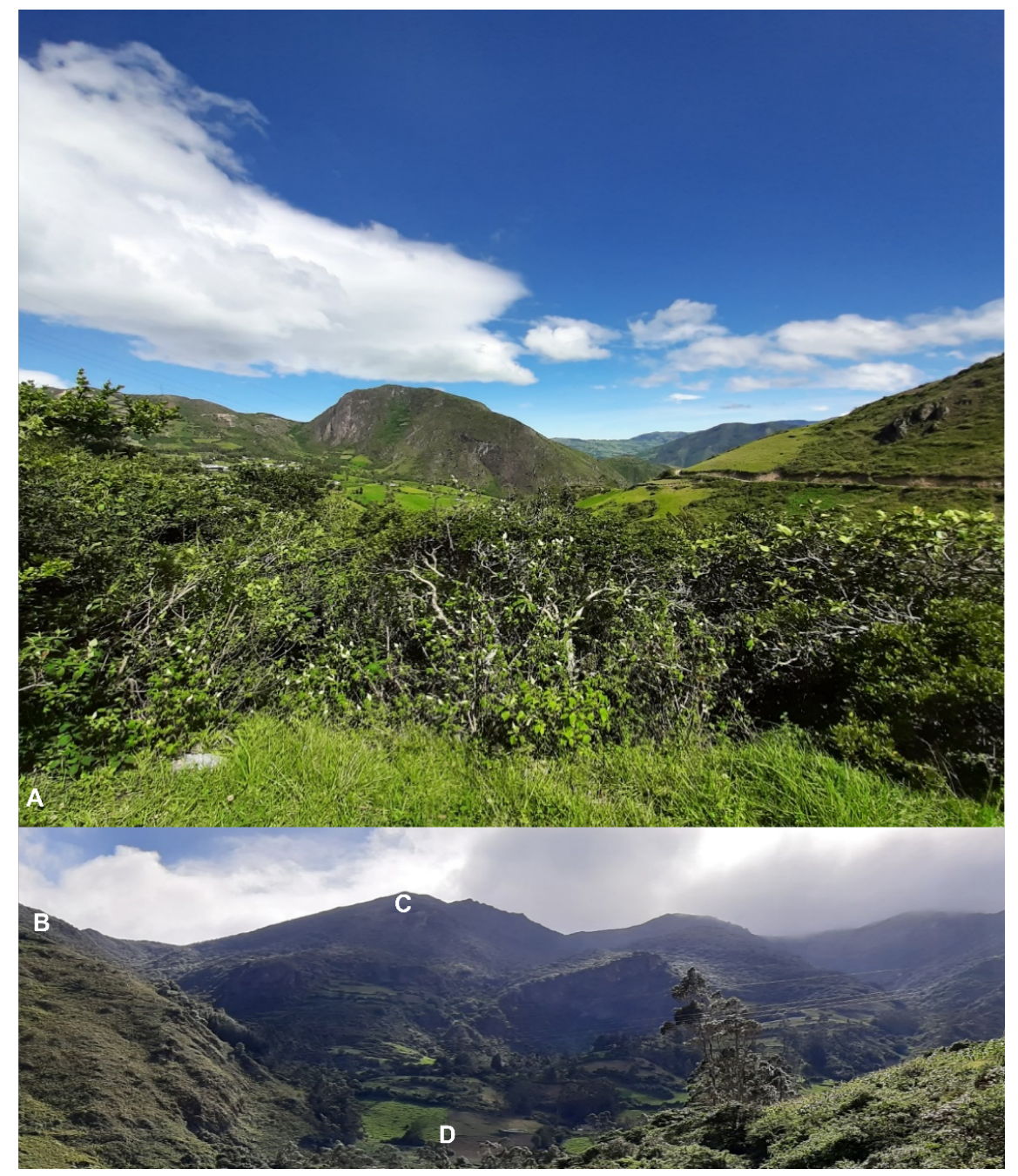

Figure 1. (A, B, C) Sampling locations in the interior of the high Andean forest of Chuchucan, CañarEcuador, which make up a biome closed by its gallery forest structure. (D) Advancement of the agricultural frontier.

Environmental DNA extraction from soil samples

Microbial DNA was extracted from $0.5 \mathrm{~g}$ of soil from each of the 100 samples using the Power Soil DNA isolation kit (MO BIO Laboratories, Carlsbad, CA, USA) according to the manufacturer's instructions, as it has been shown to be a robust method for DNA extraction from soils (Mahmoudi et al. 2011). The DNA samples were grouped into consortia composed of 5 DNA extractions, which kept altitudinal similarity (supplementary Table 2). The quality and size of the DNA were verified by electrophoresis in $1 \%$ agarose gel. Quality control of the extracted DNA was performed to measure $\left(A_{260} / A_{280}\right.$ and $A_{260} / A_{230}$ ratios). The DNA concentration was determined using Qubit Fluorometric Quantitation (Life Technologies, Carlsbad, 
CA, USA). To verify the size of PCR enriched fragments, the template size distribution was checked by running on an Agilent Technologies 2100 Bioanalyzer using a DNA 1000 chip.

PCR amplification and next generation sequencing (NGS, Illumina MiSeq)

Polymerase chain reaction (PCR) amplification of ITS hypervariable regions $(6 \mathrm{~F}-4 \mathrm{R})$, was performed using the extracted DNA as a template for amplifying an internal fragment of the ITS gene. Primers ITS 3 (5'GCA TCG ATG AAG AAC 132 GCA GC- 3'), (Macrogen, Seoul, Korea) and ITS 4 (5'-TCC TCC TAT TGA TAT GC-3'), (Macrogen), joined to a multiple identifier sequence (Illumina, Seoul, Korea). For each sample, amplicons were generated in several duplicate PCRs using mixtures $(25 \mu \mathrm{l})$ containing 25 pmol of each primer, 1x KAPA HiFi Hotstart Ready Mix (Kapa Biosystems, Wilmington, MA USA) and 10 ng of the DNA template. The PCR program consisted of an initial denaturalization stage at $95^{\circ} \mathrm{C}$ for $3 \mathrm{~min}$, 25 denaturation cycles at $95^{\circ} \mathrm{C}$ for $30 \mathrm{~s}$, primer annealing at $55^{\circ} \mathrm{C}$ for $30 \mathrm{~s}$ and an extension at $72^{\circ} \mathrm{C}$ for $30 \mathrm{~s}$, followed by one step final heating at $72^{\circ} \mathrm{C}$ for $5 \mathrm{~min}$. Amplicons of each treatment were grouped to reduce PCR variability and purified using Ampure accounts XP (Beckman Coulter, IN USA) according to the manufacturer's instructions. After PCR cleaning, the Illumina sequencing adapters were joined by a second stage of PCR using the Nextera XT index kit (Illumina Inc, Sand Diego, CA, USA). The mixture contained Nextera Index Primers 1 and $2(5 \mu \mathrm{l}), 2$ KAPA HiFi Hot Start Ready Mix $(25 \mu \mathrm{l})$, DNA $(5 \mu \mathrm{l})$ and PCR grade water $(10 \mu \mathrm{l})$ for a total volume of $50 \mu \mathrm{l}$. The PCR program in this step consisted of an initial denaturation step at $95^{\circ} \mathrm{C}$ for 3 minutes, followed by 8 denaturation cycles at $95^{\circ} \mathrm{C}$ for $30 \mathrm{~s}$, a primer annealing at $55^{\circ} \mathrm{C}$ for 30 seconds an extension at $72^{\circ} \mathrm{C}$ for 30 seconds, and a final step at $72^{\circ} \mathrm{C}$. for 5 min. Amplicons were cleaned as described above, and libraries were quantified using Qubit (Invitrogen, CA, USA). The samples were combined in equimolar quantities $(4 \mathrm{nM}$ each) and were sequenced on a Miseq platform (paired-end sequencing $2 \times 300$, considering $2 \times 150,000$ reads/sample) of Illumina in Macrogen (Seul, South Korea) in accordance with the manufacturer's instructions.

Taxonomic allocation of sequence readings and diversity index

The paired-end reading sequences generated from Illumina MiSeq were processed using the software package "Quantitative Insights into Microbial Ecology 2" (QIIME 2, v2018.6) (Caporaso et al. 2010). Briefly, readings were demultiplexed, trimmed, filtered, and merged with the DADA2 complement (Callahan 2016), keeping the sequences with a minimum quality score of 25 , a minimum length of $240 \mathrm{bp}$ for reverse readings, and a maximum length of $260 \mathrm{bp}$ for advanced readings. Merged reads collapsed into representative sequences or ASV. Then, ASVs were filtered through the novo chimera using VSEARCH (Rognes et al. 2016). The taxonomy of ASV was assigned at a 99\% sequence identity based on the UNITE v7 database (Kõljalg 2013). Non-fungal sequences were removed from the subsequent analysis, and the ASV table was rarefied to a uniform depth (100,000 sequences per sample) to reduce bias related to the depth of sequencing. Taxonomy and shared files produced in QIIME 2 were imported into R (R Core Team 2018) using the Phyloseq package (McMurdie et al. 2013) where $\alpha$ and $\beta$ diversity were calculated.

Statistical analyses

All statistical analyses were performed in R (v.3.4.3; R Core Team 2018). Phyloseq package (McMurdie et al. 2013). "Quantitative Insights into Microbial Ecology 2" (QIIME 2 v2018.6) (Caporaso et al. 2010). VSEARCH (Rognes et al. 2016). The rarefied data was used to calculate if the altitude gradient was significantly correlated with the fungi composition. For this purpose, Bray-Curtis distance calculation was applied, and permutation was set to 999. PERMANOVA analysis was calculated using the vegan $\mathrm{R}$ package (Oksanen et al. 2015).

\section{RESULTS}

In the wide range of fungi, the ITS region had shown to have a higher probability of successful identification and, therefore, was proposed as the main fungal barcode marker considered the Bar Code of Life (CBOL) (Schoch et al. 2012). However, for metagenomic data, recovered sequences from the ITS region are very short and variable. Making this region only suitable for ASVs identification analysis and not for alignment 
and phylogenetic tree analysis. The sequence lengths ranged from 35 to 301 nucleotides. A total of 2,834,735 raw readings were obtained. The average readings per sample was 141,730. After the cutting and filtering process, the reads were reduced to an average of 131,813.1 per sample. Sample location A showed the highest abundance, with an average of $675 \mathrm{ASVs}$, followed by location B with an average of $626 \mathrm{ASVs}$. The lowest abundance of ASVs was found in the sample $\mathrm{C}$ with an average of $556 \mathrm{ASVs}$ per sample (Figure 2).

Analysis of ASVs data revealed the presence of 12 taxa at the phyla level in soil samples. The most abundant taxa were Ascomycota, followed by Mortierellomycota, Basidiomycota and Mucoromycota. At the order level, it was possible to identify 42 different taxa of which the most abundant one corresponded to Mortierellales, followed by Hypocreales, andHelotiales. A total of 89 genera were identified and the most abundant taxa corresponded to Mortierella, followed by Fusarium, and Saitozyma .

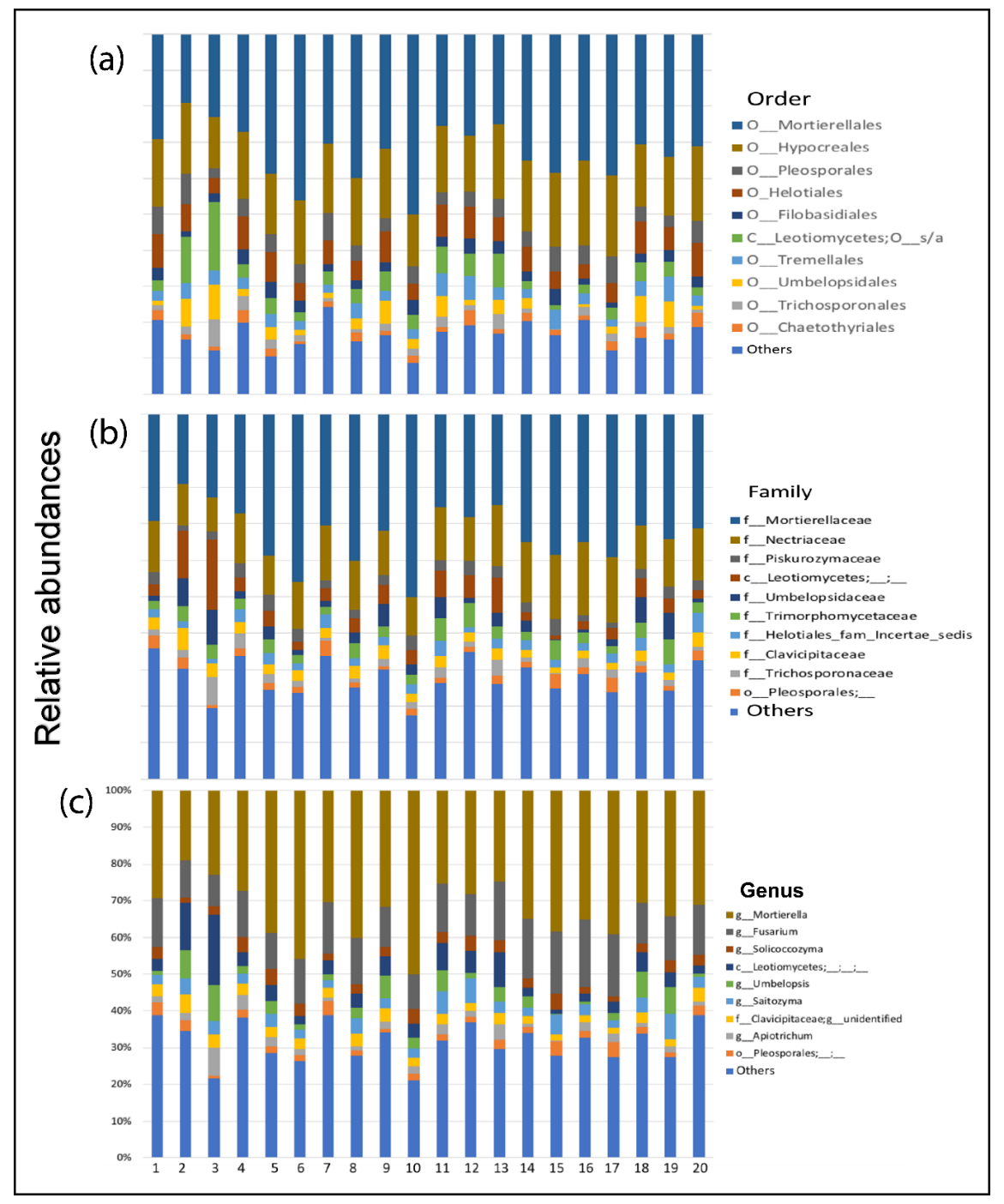

Figure 2. Fungus composition and library number of Chuchucán protective forest samples at different altitudes. Location A: 1, 2, 3, 4, 5, 6, 7; location B: 8, 9, 10, 11, 12, 13, 14; location C: 15, 16, 17, 18, 19, 20. The relative abundance of the sequences is expressed as a percentage and is show in the level of the Order (a), Family (b) and Genus (c).

With regard to the estimated alpha diversity of the different sampling locations, observed species showed 
a significantly higher value in location $\mathrm{A}$ in relation to location $\mathrm{C}$, but without difference with location $\mathrm{B}$, Shannon and Simpson indexes were not significantly different between locations (Table 2, Figure 3).

Table 2. Average of observed species, Shannon index and Simpson index, at the sampling locations A, B, and $\mathrm{C}$.

\begin{tabular}{llll}
\hline Sample location & Observed Species & Shannon Index & Simpson Index \\
\hline Location A & $675.0 \pm 66.4 \mathrm{a}$ & $4.30 \pm 0.30$ & $0.96 \pm 0.02$ \\
Location B & $626.6 \pm 56.8 \mathrm{ab}$ & $4.27 \pm 0.18$ & $0.96 \pm 0.02$ \\
Location C & $556.0 \pm 76.6 \mathrm{~b}$ & $4.27 \pm 0.25$ & $0.96 \pm 0.01$ \\
\hline
\end{tabular}

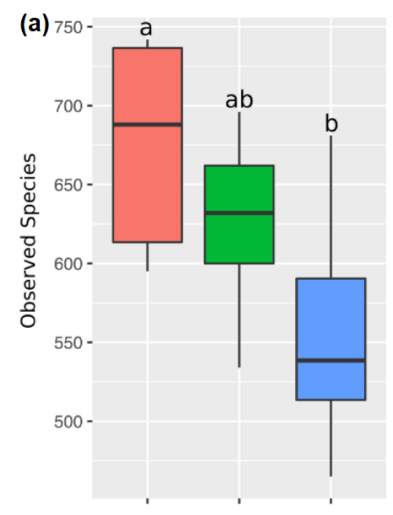

(b)
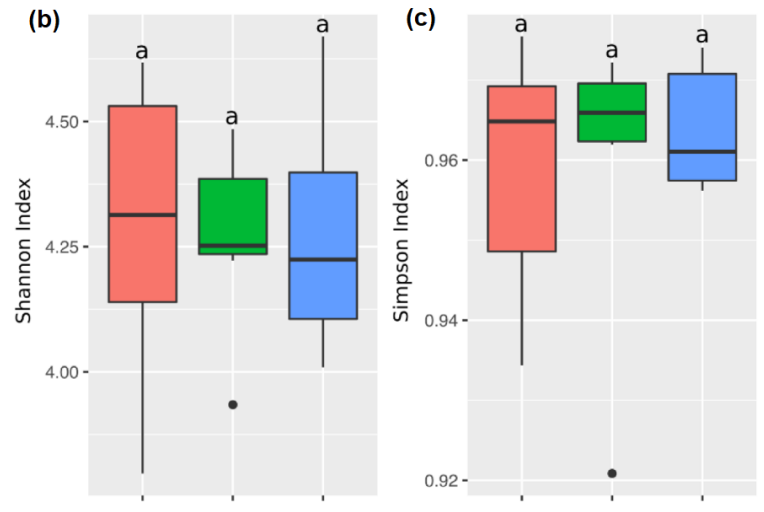

Location A官 Location B追 Location C

Figure 3. Richness (Observed Species) and alpha diversity indices (Shannon and Simpson) for fungal soil communities at different samples locations. (a) Observed Species (b) Shannon Index (c) Simpson Index. Different lowercase letters show statistical differences at p: 0.05 for ANOVA test.

Venn's analysis shows that $50 \%$ of all ASVs at genus level were common for the three sampling sites. At location A, the highest number of unique ASVs was observed with 60 , which corresponds to $10.8 \%$, while location 3 had the lowest number of unique ASVs 271 with 43 (7.8\%) (Figure 4). 


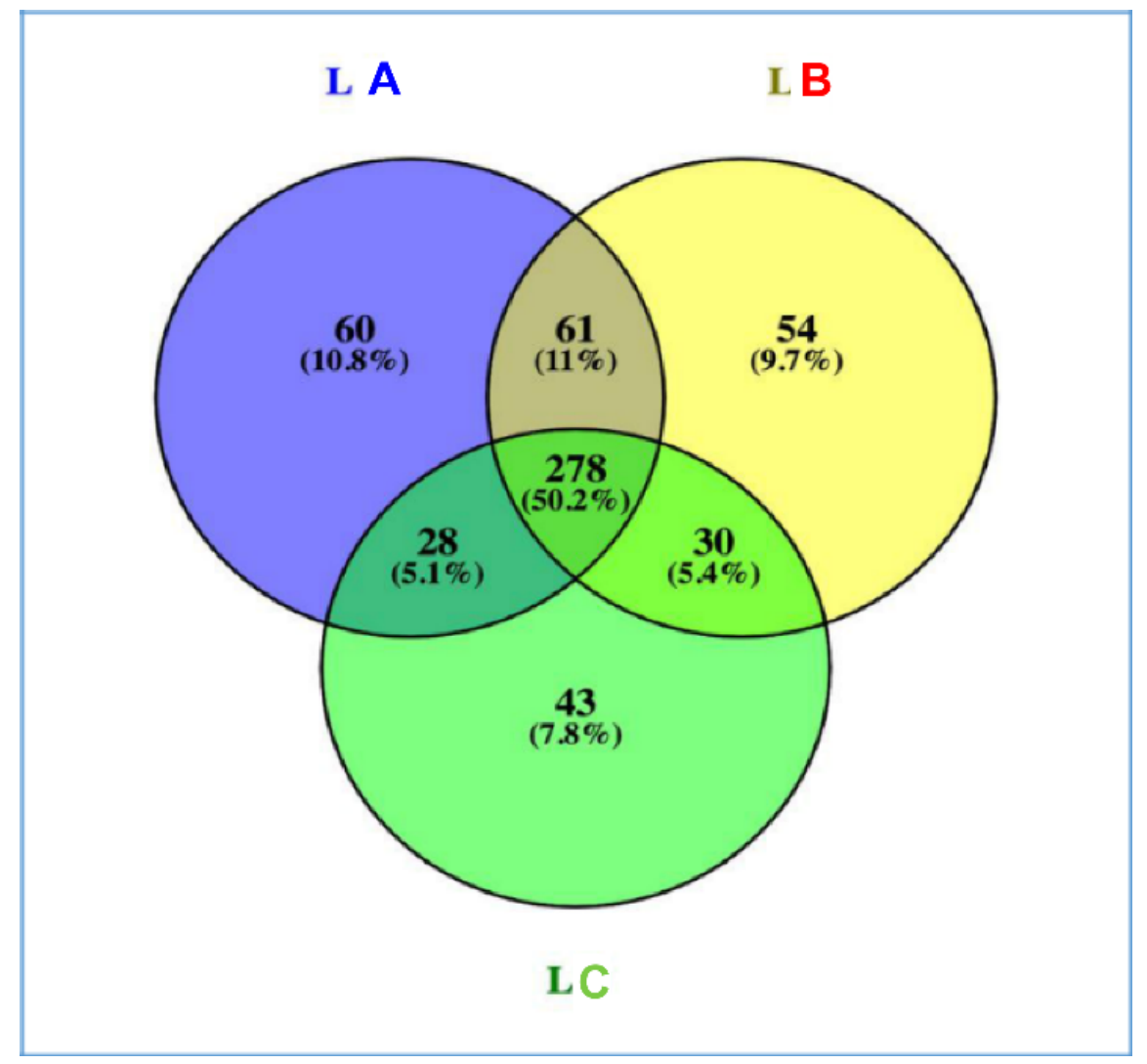

Figure 4. Venn diagram showing the genus level ASVs shared among the three sampling locations.

PERMANOVA test did not show statistical differences for betha diversity between sampled locations (p value was 0.226$)$.

\section{DISCUSSION}

A few decades ago, the introduction of molecular biology and tools such as PCR and the pros and cons of NGS can be described as a very fast procedure and that has a high stream reading performance, although the length of the reading can be limiting (400 bp). For NGS, we decided to use the ITS region, because it represents a good element among a less variable region such as LSU (Stockinger et al. 2010). NGS allowed to obtain more data at a lower cost compared to other techniques such as the Sanger sequencing.

There are very few studies of the use of NGS in soil fungal communities, in Ecuador. Most studies are oriented to the description of the diversity of arbuscular mycorrhizal fungi (AMF) and are not specific on forest soil. The studies include tropical montane forests (Haug et al. 2019) and Andean forest (Dueñas et al. 2020) associated with potato cultivation in the Andean part of Loja and Quito (Senés-Guerrero \& Schüßler 2016; Loján et al. 2017). There are also studies of the communities of AMF with plants growing in crude oil-contaminated sites in the Amazon region of Ecuador (Garcés-Ruiz et al. 2019).

The study of AMF in montane tropical forests (Duenas et al. 2010), shows that the Acaulosporaceae and Glomeraceae families presented a higher abundance of out. Our results showed a higher abundance of ASVs with Mortirelacea and Nectriaceae families. In the case of AMF, taking into account altitude gradients, Haug et al. (2019), reported that the largest number of OTUs was dominated by the genus Acaulospora and Glomu s. However, our report showed a greater abundance of ASVs with the genus Mortirella and Fusarium .

In the case of AMF associated to potato, the presence of a composite base "core" consisting mainly of 
Acaulospora sp .,Cetraspora nodosa , Claroideoglomus sp . andRhizophagus sp . strains has been escribed (Senes-Guerrero \& Schussler 2016: Lojan et al. 2017). In the present study, these species were found at a very low frequency or were not detected at all (e.g.Rhizophagus sp .). In fungal communities in areas contaminated with crude oil, diversity was very similar, dominating in this caseRhizophagus (Garces-Ruiz et al. 2019).

The most abundant genus in our study: Mortierella, is ubiquitous and has 85 species (Ainsworth et al. 2008). Mortierella is often found in correspondence with decaying leaves due to her saprophytic nature (Tamayo-Velez et al. 2018) as in the high mountain closed forest. In regard to alpha diversity, it was very similar among all sampling sites. The values reported here are similar to those found for other regions of the world with altitudes above 2,000 meters above sea level (Arguelles-Moyao et al. 2018). Others abundant genera reported here correspond to the yeasts Saitozyma sp . and Solicocoozyma sp ., which occurs in forest soils (Mašínová et al. 2017)

When reviewing the beta diversity estimated by the Bray-Curtis method, it can be observed that samples from locations $\mathrm{A}$ and $\mathrm{B}$ show a similarity in their distribution compared to location $\mathrm{C}$ which is consistent with Venn analysis showing that locations A and B share a higher percentage of the genera (10.8\%). However, the variability in the distribution of fungal communities between different altitudes was not so evident, due to the small altitude gradient used in the study ([?] 550 masl). Studies on AMF have shown that the number of shared OTUs at neighbouring elevations would explain the effect of elevation on smaller gradients, where distinct AMF communities have not been found (De Beenhouwer et al. 2015; Egan et al. 2017; Liu et al. 2015).

\section{CONCLUSIONS}

This is the first contribution on the fungal community of high Andean forest soil under the biome closed in the south of Ecuador. The system shows high diversity of phyla and genera. Some of the interesting species such as Mortierella sp. and Saitozyma sp. could have biotechnological applications (Carota et al. 2018: Gorte et al. 2020). We recommend NGS for the characterization of filamentous fungi in soil, depending on the required level of taxonomic discrimination. However, molecular research should be complemented by studies on taxonomy, ecology and physiology of filamentous soil fungi in order to better understand the distribution and the benefits that each species of fungus could obtain from the soil. Such studies would also be important for the management, preservation, and restoration of the Andes soils habitat.

\section{ACKNOWLEDGMENTS}

To the Faculty of Agricultural Sciences of the University of Talca, Chile for the PhD Scholarship. We would like to thank Eduardo Chica Ph.D. teaching researcher from the Faculty of Agricultural Sciences of Universidad de Cuenca, Ecuador for the support provided. To Andres Yarzabal Ph.D. teaching researcher at the Catholic University of Cuenca, Ecuador for his support. To the private company ID Metagenomics Canar-Ecuador, for their help in the analysis of metagenomic data. To the kind people of the Chuchucan community, Canar, Ecuador for allowing us to study their forest soils.

\section{CONFLICT OF INTEREST}

The authors declare that they have no competing interests.

\section{AUTHOR CONTRIBUTIONS}

VA conceived, designed and performed the experiments, contributed reagents/materials/analysis tools; CS, VA analyzed the data; VA, CS wrote the paper.

\section{DATA AVAILABILITY STATEMENT}

High performance sequencing datasets from this study were deposited in the NCBI Biosamples data with access numbers SAMN16663766, SAMN16663767 and SAMN16663768 for site A, B and C ITS DNA metabarcoding libraries, respectively. 


\section{ORCID}

Adrian Valdez https://orcid.org/0000-0002-1902-8383

REFERENCES

Ainsworth G, Ainsworth, Bisby's (2008) Dictionary of the fungi. Wallingford, Oxon UK

Arguelles-Moyao A, Garibay-Orijel R (2018) Ectomycorrhizal fungal communities in high mountain conifer forests in central Mexico and their potential use in the assisted migration of Abies religiosa. Mycorrhiza 28:509-521

Amir A, McDonald D, Navas-Molina JA, Kopylova E, Morton JT, Xu ZZ (2017) Deblur rapidly resolves single-nucleotide community sequence patterns. mSystems 2:e00191-16

Callahan BJ (2016) DADA2: High-resolution sample inference from Illumina amplicon data. Nature Methods $13: 581-583$

Caporaso JG, Kuczynski J, Stombaugh J, Bittinger K, Bushman FD, Costello EK, Huttley GA (2010) QIIME allows analysis of high-throughput community sequencing data. Nature Methods 7:5-335

Callahan BJ, McMurdie PJ, Rosen MJ, Han AW, Johnson AJ, Holmes SP (2016) DADA2: High-resolution sample inference from Illumina amplicon data. Nature Methods 13:581-583

Carota E, Crognale S, D'Annibale A, Petruccioli M (2018) Bioconversion of agro-industrial waste into microbial oils by filamentous fungi. Process Safety and Environmental Protection 117:143-151

De Beenhouwer M, Muleta D, Peeters B, Van Geel M, Lievens B, Honnay O (2015) DNA pyrosequencing evidence for large diversity differences between natural and managed coffee mycorrhizal fungal communities. Agronomy for Sustainable Development 35:241-249

Donald J, Weir I, Bonnett S, Maxfield P, Ellwood MDF (2018) The relative importance of invertebrate and microbial decomposition in a rainforest restoration project. Restoration Ecology 26:220-226

Duenas JF, Camenzind T, Roy J, Hempel S, Homeier J, Suarez JP, Rillig MC (2020) Moderate phosphorus additions consistently affect community composition of arbuscular mycorrhizal fungi in tropical montane forests in southern Ecuador. New Phytologist, 227: 1505-1518

Edgar RC (2016) UNOISE2: improved error-correction for Illumina 16 S and ITS amplicon sequencing. BioRxiv 081257

Egan CP, Callaway RM, Hart MM, Pither J, Klironomos J (2017) Phylogenetic structure of arbuscular mycorrhizal fungal communities along an elevation gradient. Mycorrhiza 27:273-282

Eren AM, Maignien L, Sul WJ, Murphy LG, Grim SL, Morrison HG (2013) Oligotyping: differentiation between closely related microbial taxa using data from the 16S rRNA gene. Methods in ecology and evolution 4:1111-1119

Eren AM, Morrison HG, Lescault PJ, Reveillaud J, Vineis JH, Sogin ML (2015) Minimal entropy decomposition: unsupervised oligotyping for sensitive partitioning of high-throughput marker gene sequences. The ISME journal, J9:968-979

Fierer N (2017) Embracing the unknown: unraveling the complexities of the microbiome of the ground. Nature Reviews Microbiology 15:10-579

Garces-Ruiz M, Senes-Guerrero C, Declerck S, Cranenbrouck S (2019) Community composition of arbuscular mycorrhizal fungi associated with native plants growing in a petroleum-polluted soil of the Amazon region of Ecuador. Microbiology Open 8:703

Genney, DR, Anderson, IC, Alexander IJ (2005) Fine-scale distribution of pine xtomycorrhizas and their extrametrical mycelium. New Phytologist 170:381-390 
Gorte O, Hollenbach R, Papachristou I, Steinweg C, Silve A, Frey W, .. Ochsenreither K (2020) Evaluation of downstream processing, extraction, and quantification strategies for single cell oil produced by the oleaginous yeasts Saitozyma podzolica DSM 27192 andApiotrichum porosum DSM 27194. Frontiers in Bioengineering and Biotechnology 8:355

Haug I, Setaro S, Suares JP (2019) Species composition of arbuscular mycorrhizal communities changes with elevation in the Andes of South Ecuador. PloS One 14- 8 e0221091

Jansson JK, Hofmockel KS (2018) Soil microbiome: from metagenomics to metaphenomics. Current Opinion in Microbiology 43:162-168

Keating PL. (1998). Effects of anthropogenic disturbances on Paramo vegetation in Podocarpus National Park. Ecuador Physical Geography 19:221-238

Koide RT, Shumway DL, Xu B, Sharda JN (2007) On temporal partitioning of a community of ectomycorrhizal fungi. New Phytologist 174:420-429

Koljalg U, Larsson KH, Abarenkov K, Nilsson RH, Alexander IJ, Eberhardt U, Erland, S, Hoiland K, Kjoller R, Larsson E (2005) UNITE: a database providing web-based methods for themolecular identification of ectomycorrhizal fungi. New Phytologist 166:0631068

Koljalg U (2013) Towards a unified paradigm for sequence-based identification of fungi. Molecular Ecology 22:5271-5277

Lindahl BD, Nilsson RH, Tedersoo L, Abarenkov K, Carlsen T, Kjoller R, Kauserud H (2013) Fungal community analysis by high-throughput sequencing of amplified markers a user's guide. New Phytologist, 199:288-299

Liu L, Hart MM, Zhang J, Cai X, Gai J, Christie P, Klironomos JN (2015) Altitudinal distribution patterns of AM mushroom assemblages in a Tibetan alpine grassland. Ecology of Microbiology FEMS 91:7

Lojan P, Senes-Guerrero C, Suarez JP, Kromann P, Schussler A, Declerck S. 2017. Potato field-inoculation in Ecuador with Rhizophagus irregularis : no impact on growth performance and associated arbuscular mycorrhizal fungal communities. Symbiosis 273:45-56

Malik S, Beer M, Megharaj M, Naidu R (2008). The use of molecular techniques to characterize the microbial communities in contaminated soil and water. Environment International 34-265- 276

McMurdie PJ, Holmes S (2013) Phyloseq: An R package for reproducible interactive analysis and graphics of microbiome census data. PLOS ONE 8:61-217

Mahmoudi N, Slater GF, Fulthorpe RR (2011) Comparison of commercial DNA extraction kits for isolation and purification of bacterial and eukaryotic DNA from PAH- contaminated soils. Canadian Journal of Microbiology 57:623-628

Mašínová T, Bahnmann BD, Větrovský T, Tomšovský M, Merunková K, Baldrian P (2017) Drivers of yeast community composition in the litter and soil of a temperate forest. De Boer W editor FEMS Microbiology Ecology 93:223

Moncrieff GR (2016) Revising the biome concept for understanding and predicting global change impacts. Journal of Biogeography 43:863-873

Mueller GM, Schmit JP, Leacock PR, Buyck B, Cifuentes J, Desjardin DE, Halling RE, Hjortstam K, Iturriaga T, Larsson KH, Lodge DJ (2007) Global diversity and distribution of macrofungi. Biodiversity and Conservation 16:37-48

Needham DM, Sachdeva R, Fuhrman JA (2017) Ecological dynamics and co-occurrence among marine phytoplankton, bacteria and myoviruses shows microdiversity matters. The ISME journal, 11:1614-1629 
Nordén B, Paltto H (2001) Wood-decay fungi in hazel wood: species richness correlated to stand age and dead wood features. Biological Conservation 101:1-8

Oksanen J, Blanchet FG, Kindt R, Legendere P, Minchin PR, O'Hara RB, Wagner H (2015) Vegan: community ecology package. $\mathrm{R}$ package vegan version $2.2-1$

Pausas JG, Bond WJ (2020) Alternative biome states in terrestrial ecosystems. Trends in Plant Science 25:250-263

Peay KG, Kennedy PG, Talbot JM (2016) Dimensions of biodiversity in the Earth mycobiome. Nature Reviews Microbiology 14:434-447

Quince C, Lanzen A, Davenport RJ, Turnbaugh PJ (2011) Removing noise from pyrosequenced amplicons. BMC Bioinformatics 12:38

R Core Team (2018) R: A Language and Environment for Statistical Computing. R Foundation for Statistical Computing Vienna. https://www.R-project.org

Rognes T, Flouri T, Nichols B, Quince C, Mahe F (2016) VSEARCH: a versatile open source tool for metagenomics. Peer J e2584

Senes-Guerrero C, Schussler A (2016) A conserved arbuscular mycorrhizal fungal core- species community colonizes potato roots in the Andes. Fungal Diversity 77:317-333

Schmeisser C, Steele H, Streit, WR (2007) Metagenomics, biotechnology with non- culturable microbes. Applied microbiology and biotechnology, 75:955-962

Schoch CL, Seifert KA, Huhndorf S, Robert V, Spouge JL, Levesque CA, Chen W, Bolchacova E, Voigt K, Crous PW, Miller AN (2012) Nuclear ribosomal internal transcribed spacer (ITS) region as a universal DNA barcode marker for fungi. Proceedings of the National Academy of Sciences109:6241-6246

Steele HL, Streit WR (2005) Metagenomics: Advances in ecology and biotechnology. FEMS Microbiology Letters 247:105-111

Stockinger H, Kruger M, Schussler A (2010) DNA barcoding of arbuscular mycorrhizal fungi. New Phytologist 187:461-474

Steele EA, Tucker, PAC't H, Schuemie MJ (2009) Previous publications based on literature for gene regulatory networks. Bioinformatics 14:1768-1774

Seifert KA (2009) Progress towards DNA barcoding of fungi. Molecular Ecology Resources 9:83-89

Sierra R, Campos F, Chamberlin J (2002) Assessing biodiversity conservation priorities: ecosystem risk and representativeness in continental Ecuador. Landscape and Urban Planning 59:95-110

Tamayo-Velez A, Osorio NW (2018) Soil fertility improvement by litter decomposition and inoculation with the fungus Mortierella sp . in avocado plantations of Colombia. Communications in Soil Science and Plant Analysis 49:139-147

Tapia-Armijos MF, Homeier J, Espinosa CI, Leuschner C, Cruz M (2015) Deforestation and forest fragmentation in South Ecuador since the 1970 losing a hotspot of biodiversity. PloS One 10:e0133701

Tikhonov M, Leach RW, Wingreen NS (2015) Interpretation of 16S metagenomic data without clustering to achieve sub-OTU resolution. The ISME journal 9:68-80

Thies B, Meyer H, Nauss T, Bendix J (2012) Projecting land-use and land-cover changes in tropical mountain forest of Southern Ecuador. Journal of Land Use Science 1-33

Torsvik V, Ovreas L, (2002) Microbial diversity and function in soil: from genes to ecosystems. Current Opinion in Microbiology 5:240-245 
Uroz S, Ioannidis P, Lengelle J, Cebron A, Morin E, Buee M (2013) The essays functional and metagenomic analyzes reveal differences between communities microbial inhabiting the soil horizons of a fir plantation of Norway. PLoS ONE 8:e55929

Van der Heijden MGA, Martin FM, Selosse MA, Sanders IR (2015) Mycorrhizal ecology and evolution: the past, the present, and the future. New Phytologist 205:1406-1423 